\title{
The study of the differences about the development of body patterning of city girls of the Korean nationality in different ghettos
}

\author{
LI Gang ${ }^{1}$, Li Tong ${ }^{2}$, Song De-hai ${ }^{1}$, Wang Liang ${ }^{1}$ \\ ${ }^{1}$ Northeast Normal University, Changchun, China \\ ${ }^{2}$ Jilin Animation Institute, Changchun, China
}

\begin{abstract}
Objectives: To ensure the characteristics and the law of the development of body patterning of Korean girls who live in the city in different ghettos and to provide a basis for the improvement of students' health developing. Methods: According to the requirements of the "Detailed Rules For the Implementation of the National Students' Physic and Health Survey in 2010". We made survies on Korean students in different ghettos and used the SPSS to analyse the datas in statistic ways. Conclusions: There existed obvious differences in the development process and development levels of Korean city girls' body patterning in different ghettos .Existing the trend that the development process of city girls who live in the Korean ghettos is earlier and shorter than those who live in the Han ghettos .Besides, the height of Han nationality students is obviously higher than the Korean students.

Index Terms - ghettos, the Korean nationality, city girls, body patterning, difference

Different ethnic differences in body shape Korean girls district city development level, development speed is a result of comprehensive effect of multiple genetic factors and environmental factors. This paper attempts to Korean nationality, Han nationality area Korean city girls physical development, development level and its influencing factors investigation, determine the difference.
\end{abstract}

\section{Objects and Methods}

\section{A. Objects}

The Han nationality area (Jilin province Changchun City) 7-18 years old Korean city girl, was born in area of Han nationality, studied at the national school. Parents are Korean, and have settled in Han area.

Korean inhabited area (Yanji Yanbian) 7-18 years old Korean city girl, her parents for Korean, born to Korean community.

\section{B. Index and Method}

Physical indicators, including height, sitting height, body weight, chest circumference of 4 .

According to the "test method of national student fitness and health survey detection rules" about body shape.

\section{The Research Results}

Table 1, 2shows Korean inhabited area 7-18 years old Korean city girls (hereinafter referred to as towards toward), Han area 7-18 years old Korean city girls (hereinafter referred to as the Han Dynasty) and 7-18 years old Han city girls (hereinafter referred to as the Han nationality) the results of the survey indicators of body shape.

Table 1 Different level of development, the Han nationality live in city girls body shape area

\begin{tabular}{|c|c|c|c|c|c|c|c|c|c|c|c|c|c|c|c|c|}
\hline Ind & & 7 & 8 & 9 & 10 & 11 & 12 & 13 & 14 & 15 & 16 & 17 & 18 & Ave & $7 \sim 18$ & Growth \\
\hline & $\mathrm{K}=\mathrm{K}$ & 126.08 & 130.14 & 134.53 & 142.94 & 148.53 & 152.53 & 156.29 & 155.71 & 156.98 & 158.66 & 158.18 & 158.11 & 148.22 & 32.04 & 2.91 \\
\hline \multirow[t]{3}{*}{$\mathrm{H}$} & $\mathrm{H}=\mathrm{K}$ & 118.39 & 126.96 & 129.56 & 139.25 & 144.62 & 152.34 & 156.60 & 159.52 & 160.32 & 161.16 & 160.60 & 160.32 & 147.47 & 41.93 & 3.81 \\
\hline & $\mathrm{H}$ & 125.12 & 133.55 & 141.22 & 145.94 & 155.16 & 158.59 & 161.41 & 160.53 & 163.38 & 163.34 & 163.82 & 163.67 & 152.98 & 38.55 & 3.50 \\
\hline & $\mathrm{K}-\mathrm{K}$ & 69.63 & 71.11 & 73.12 & 76.38 & 79.92 & 82.94 & 85.22 & 85.32 & 8634 & 87.49 & 86.90 & 8637 & 8089 & 1674 & 152 \\
\hline \multirow[t]{2}{*}{ SH } & H-K & 65.03 & 69.61 & 70.95 & 75.55 & 77.92 & 81.13 & 84.36 & 84.87 & 86.84 & 87.52 & 87.72 & 88.61 & 80.01 & 23.58 & 2.14 \\
\hline & $\mathrm{H}$ & 66.66 & 71.71 & 76.37 & 80.45 & 82.00 & 80.26 & 80.60 & 80.39 & 83.15 & 85.23 & 85.31 & 84.49 & 79.72 & 17.83 & 1.62 \\
\hline \multirow[t]{3}{*}{ W } & $\mathrm{H}-\mathrm{K}$ & 23.03 & 27.56 & 28.29 & 35.33 & 38.05 & 43.38 & 49.78 & 54.82 & 54.41 & 54.20 & 54.66 & 56.66 & 43.35 & 33.63 & 3.06 \\
\hline & $\mathrm{H}$ & 26.66 & 30.89 & 34.82 & 35.96 & 42.69 & 48.80 & 50.60 & 50.55 & 54.67 & 54.33 & 55.05 & 54.03 & 44.92 & 27.37 & 2.49 \\
\hline & K-K & 60.65 & 63.03 & 65.27 & 68.73 & 72.83 & 74.91 & 77.47 & 80.18 & 78.99 & 82.38 & 80.93 & 80.73 & 73.84 & 20.09 & 1.83 \\
\hline C & H-K & 58.32 & 59.78 & 63.61 & 68.47 & 70.63 & 74.71 & 79.76 & 85.06 & 85.10 & 82.54 & 84.12 & 85.48 & 74.80 & 27.16 & 2.47 \\
\hline
\end{tabular}


Table 2 Comparison of different level of development, the Han nationality live in city girls body shape area

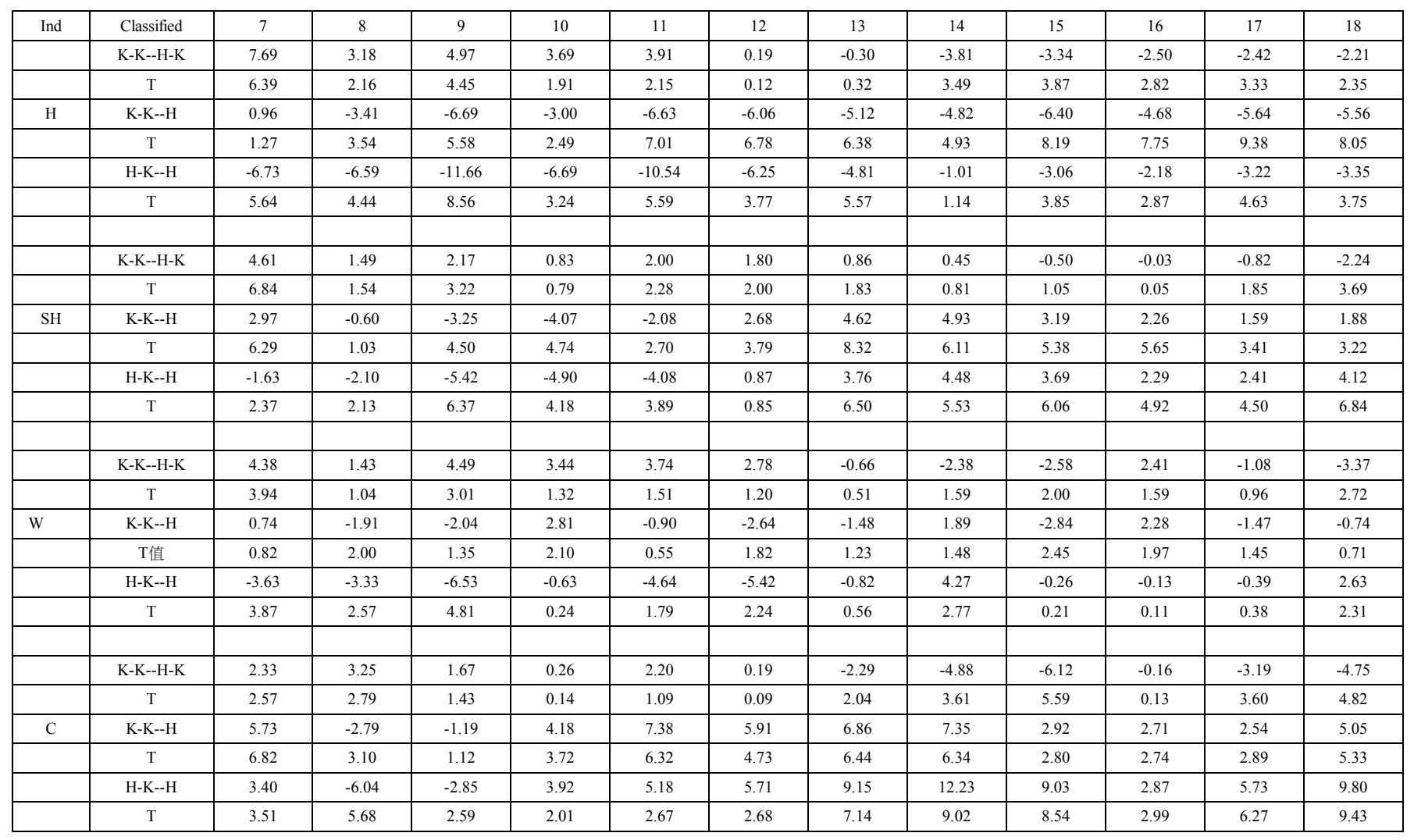

Annotations:H-height;SH-setting height; $\mathrm{W}$-weight;C-chest measurement;

\section{A. Differences in Body Shape Indicators}

\section{a) Differences in Height Growth Level}

Table 1, 2shows toward the students toward the average height is slightly higher than the Han - Dynasty similar students. Between 7-18 years, Han - towards students height growth values, with an average annual growth rate of value is greater than that in toward the students, the growth rate significantly more than the in - towards students. In the process of growth and development, between 7-12 years to students of all ages at the height levels were significantly higher than that of Han - towards students, but after 13 years, Han - Dynasty students of all ages are significantly more than in height development toward the students.

In accordance with the annual growth rate the highest number and adjacent to the highest life identified as the sensitive period of growth and development. The two area students height development sensitive period was 10-11 years old. 7-11 years old, looked toward the students height increased by $22.45 \mathrm{~cm}$, accounting for 7-18 years the total growth $70.08 \%$; Han - Dynasty students height increased by $26.23 \mathrm{~cm}$, accounting for 7-18 years the total growth of $62.71 \%$. Growth sensitivity before and during the process of growth and development, the development level of Han height toward the students was significantly lower than that in toward the students. And the sensitive period and after the process of growth and development, Chinese - towards the height of students sustainable development process and the development level was significantly higher than that toward the students toward. Inference, Korean nationality area Korean city girls fast height growth process early in the Han area of Korean students.

No matter at or toward the city towards the Chinese girls, the overall level of the height growth was significantly lower than that of the Han students.

Research results show that, 7 edge toward the height of students was significantly higher than that of the Han students. To further prove the previous paper, "before the age of 7, height difference in Han students of Korean nationality, existence".

\section{b) Differences of Sitting Height Development Level}

Table 1, 2 shows, 7-18 edge toward the average student sit slightly higher than the Han - towards their fellow students. With the growth of the age, significant changes in Chinese students, differences toward toward the student body development existence. Between 7-14 years, moving toward the students of all ages sitting height were greater than Han towards students; $15-18$ years, Han - Dynasty students sitting height is greater than that in toward the students. That, along with the age growth, toward the students in body length is greater than the differences between Chinese - towards the students decreased gradually, and Han students sit high development toward greater than the difference in toward the students gradually increase. 
Between 7-18 years, the Han - Dynasty students sit high total growth, annual growth values were higher in toward the students. Description of Han - towards the students sit high development continued to grow significantly over toward the students toward.

Factors still exist and - 7 years towards students and Han students sitting height difference toward. In the whole development process toward the students sit high on or before the Han Dynasty students.

Two live in the region to the students sit high sensitive developmental period is $10-11$ years old. 7-11 years old, looked toward the student sitting height increased by 10.29 $\mathrm{cm}$, accounting for 7-18 years the total growth $61.47 \%$; Han Dynasty students sitting height increased by $12.89 \mathrm{~cm}$, accounting for 7-18 years the total growth of $54.67 \%$. In this stage, the Han - Dynasty students sit high development level is lower than in toward the students. The process of growth and development after, Han - towards the students sit high sustained growth, development speed and development level was significantly higher than that toward the students toward.

Two live in the region to Korean students sit high development level were significantly higher than that of the Han students, demonstrates the Korean students body length was significantly higher than Han students.

\section{c) Differences in Body Weight Development Level}

Table 1, 2 shows, 7-18 edge - average weight was significantly greater than that in Han students toward the students. Between 7-18 years, Han - toward the student growth, with an average annual growth rate of value are obviously greater than in toward the students. In the development process of the whole, the existence of different ages of the body weight growth rate, growth is not a development trend. For example, 7-12 years old, at the level of development in the students' is significantly greater than the weight of Han - towards students; after the age of 13, this difference narrows gradually, and changed, both Han towards students weight development level is greater than that in gradually toward the students.

Body weight development sensitive period, facing toward the students 9-10 years, Han - Dynasty students aged 10-11 years, Han students aged 11-12.

Compared with Han students, between 7-12 years, Han Dynasty students weight development level is significantly lower than the Han students; after the age of 13, this difference seems to be not obvious. The overall level of Han students weight development better than Korean students. The overall level of Korean nationality students weight development is obviously larger than the region inhabited by Han students.

\section{d) Differences in Chest Development Level}

Table 1 ,2shows Han - toward the average student body around the overall level of development is better than at the average chest towards students, a difference of $0.96 \mathrm{~cm}$. Between 7-18 years, Han - toward the student growth of 27.16 $\mathrm{cm}$, with an average annual growth of $2.47 \mathrm{~cm}$, were significantly higher than that toward the students toward.
There is in toward the student body circumferences of the early Han Han - Dynasty toward the students, student body circumference sustainable development level is higher than the trend towards toward the students.

Han - Dynasty students bust development sensitive period for 13-14 years old, looked toward the students 10-11 years old, about 3 years later. The Han - Dynasty student body circumference development mainly concentrated in the chest circumference growth stages sensitive period and after the.

Two kinds of settlements Korean city girls body circumference development is obviously better than that of Han students.

To sum up, the overall level of development of Korean nationality area Korean city girls height, sitting height, body weight were greater than Han areas of similar students, while the bust is significantly less than the Han area of Korean students.

Between 7-18 years, during the Han area of Korean students body shape indicators of growth rate, growth were significantly larger than the Korean inhabited area of Korean students. With the growth of the age, Korean inhabited area of Korean students, sitting height, body weight, chest circumference were significantly greater than the Han nationality area Korean students gradually reduced, and form a Han area students height, sitting height, body weight, chest circumference was significantly greater than the development situation of Korean nationality area students. Before the age of 7, differences between the two kinds of settlements Korean students height, sitting height, body weight, chest circumference index has existed, the development of Korean nationality students was better than the Han nationality area students.

The sensitive period, Korean inhabited area of Korean students in height, sitting height growth slow growth or even stagnation. While the Han Chinese communities of Korean and Han students trend to continue growth.

Han students height was significantly higher than that of two kinds of settlements of Korean students. Two kinds of settlements of Korean students in body length was longer than that of the Han students.

The peak age and weight growth process, the Han nationality area of Korean students later than Korean inhabited area of Korean students. While Han students weight obviously later than Korean students. With the growth of the age, the Han nationality area of Korean students weight development level is significantly lower than the characteristic difference of Han students gradually decreases or not obvious. The overall level of Han students weight development better than Korean students.

\section{B. Differences Derived Body Shape Index}

Table 3, 4shows the results of the survey, Korean nationality, Han girls 7-18 years old city district area 7-18 years old 7-18 years old Han city girls and girls body shape of the derivative indexes. 
Table3 In different area, Han City Girls Derived Body Shape Index

\begin{tabular}{|c|c|c|c|c|c|c|c|c|c|c|c|c|c|c|c|c|}
\hline Ind & & 7 & 8 & 9 & 10 & 11 & 12 & 13 & 14 & 15 & 16 & 17 & 18 & Ave & $7 \sim 18$ & Growth \\
\hline & K-K & 55.25 & 54.65 & 54.36 & 53.45 & 53.81 & 54.39 & 54.58 & 54.89 & 55.05 & 55.16 & 54.95 & 54.64 & 54.60 & -0.61 & -0.06 \\
\hline \multirow[t]{3}{*}{$\mathrm{SH}$} & $\mathrm{H}-\mathrm{K}$ & 54.93 & 54.82 & 54.76 & 54.28 & 53.92 & 53.26 & 53.91 & 53.23 & 54.18 & 54.33 & 54.63 & 55.28 & 54.29 & 0.35 & 0.03 \\
\hline & $\mathrm{H}$ & 53.28 & 53.71 & 54.12 & 55.12 & 52.84 & 50.60 & 49.94 & 50.04 & 50.89 & 52.19 & 52.08 & 51.62 & 52.20 & -1.66 & -0.15 \\
\hline & K-K & 48.08 & 48.38 & 48.50 & 48.07 & 48.98 & 49.11 & 49.63 & 51.65 & 50.35 & 51.94 & 51.19 & 51.12 & 49.75 & 3.04 & 0.28 \\
\hline \multirow[t]{2}{*}{$\mathrm{C}$} & H-K & 49.28 & 47.08 & 49.11 & 49.11 & 48.79 & 48.98 & 50.93 & 53.34 & 53.11 & 51.23 & 52.39 & 53.37 & 50.56 & 4.09 & 0.37 \\
\hline & $\mathrm{H}$ & 43.89 & 49.32 & 47.13 & 44.30 & 42.21 & 43.51 & 43.71 & 45.35 & 46.56 & 48.78 & 47.85 & 46.24 & 45.74 & 2.35 & 0.21 \\
\hline
\end{tabular}

Table4 In different area, Han City Girls derived body shape index difference comparison

\begin{tabular}{|c|c|c|c|c|c|c|c|c|c|c|c|c|c|}
\hline Ind & classify & 7 & 8 & 9 & 10 & 11 & 12 & 13 & 14 & 15 & 16 & 17 & 18 \\
\hline & K-K--H-K & 0.32 & -0.17 & -0.40 & -0.83 & -0.11 & 1.13 & 0.67 & 1.66 & 0.87 & 0.83 & 0.32 & -0.64 \\
\hline & $\mathrm{T}$ & 1.19 & 0.43 & 1.47 & 1.97 & 0.30 & 4.03 & 1.92 & 4.50 & 2.99 & 3.05 & 1.55 & 2.25 \\
\hline \multirow[t]{6}{*}{$\mathrm{SH}$} & K-K--H & 1.97 & 0.94 & 0.24 & -1.67 & 0.97 & 3.79 & 4.64 & 4.85 & 4.16 & 2.97 & 2.87 & 3.02 \\
\hline & $\mathrm{T}$ & 7.81 & 3.13 & 0.66 & 4.28 & 2.61 & 11.15 & 14.25 & 10.45 & 11.94 & 14.85 & 12.03 & 10.16 \\
\hline & H--H & 1.65 & 1.11 & 0.64 & -0.84 & 1.08 & 2.66 & 3.97 & 3.19 & 3.29 & 2.14 & 2.55 & 3.66 \\
\hline & $\mathrm{T}$ & 5.30 & 2.62 & 1.54 & 1.85 & 2.25 & 7.04 & 10.99 & 7.23 & 9.97 & 8.54 & 9.96 & 13.60 \\
\hline & K--H & -1.20 & 1.30 & -0.61 & -1.04 & 0.19 & 0.13 & -1.30 & -1.69 & -2.76 & 0.71 & -1.20 & -2.25 \\
\hline & $\mathrm{T}$ & 1.86 & 1.88 & 0.78 & 1.07 & 0.18 & 0.12 & 1.87 & 1.88 & 3.94 & 0.97 & 2.17 & 3.30 \\
\hline \multirow[t]{4}{*}{$\mathrm{C}$} & K--H & 4.19 & -0.94 & 1.37 & 3.77 & 6.77 & 5.60 & 5.92 & 6.30 & 3.79 & 3.16 & 3.34 & 4.88 \\
\hline & $\mathrm{T}$ & 7.32 & 1.62 & 1.94 & 5.21 & 9.56 & 7.39 & 9.27 & 8.18 & 6.00 & 5.27 & 6.30 & 8.21 \\
\hline & H- $\mathrm{H}$ & 5.39 & -2.24 & 1.98 & 4.81 & 6.58 & 5.47 & 7.22 & 7.99 & 6.55 & 2.45 & 4.54 & 7.13 \\
\hline & $\mathrm{T}$ & 7.52 & 3.36 & 2.58 & 4.75 & 6.26 & 4.77 & 9.70 & 9.86 & 10.01 & 4.28 & 8.33 & 10.64 \\
\hline
\end{tabular}

\section{a) Sitting height index (sitting height / Height x 100)}

Table 3 shows that the different communities, Korean city tall girls sit development trend of high index average. Towards toward the students, Chinese students - in the index average curve with a "V" shape, namely after birth to prepubertal generally decreased with age, and then increased with the increasing of age. That spurt of body height growth was mainly the following limb growth is prominent, spurt height increases as the trunk growth as the main development trend.

From the two area students index contrast (Table 4), 8-11 edge toward the student is slightly less than the Han students aged 12-17 in, significantly larger than the Han - Dynasty students. As a result of the two settlements students height sensitive period is consistent (in 10-11 years old or so), can also explain the former - sensitive period and towards students height growth process of lower limb growth significantly greater than the Han - Dynasty students; 13-18 years old, on trunk growth as the main features of the Han - Dynasty students more obvious.

The two area of Korean students sitting height index were higher than Han students, in the Han students height growth process of lower limb growth than Korean students, torso length less than Korean students.

\section{b) Height chest circumference index (chest girth / Height $x$ 100)}

The index reflects the thoracic development status, indicating the body size. According to the index can be divided into broad chest size (\&gt; 50), medium type chest (approximately equals 50) and narrow chest type (\&lt; 50).

According to the index of Somatotype Characteristics, numerical 7-13 edge toward the students, 7-12 years old Han Dynasty students index is less than 50 , judge for the narrow chest type characteristics. Then numerical students of all ages index were significantly more than 50 , judge for the wide chest type characteristics. Korean city girls thoracic development trend from narrow to wide chest type chest.

7-18 years old Han - Dynasty students the average value is 50.56 , more than 50 , have wide chest type more obvious characteristics of the overall level of.

7-18 edge toward the students the average value is 49.75 , approximately equal to 50 , with the characteristics of moderately wide chest type level.

The development of Han students average index curve conforms to the development rule, the average value of 7-18 years old was 45.74 , with a narrow chest type characteristic.

\section{Summary}

The overall level of development of Korean nationality area Korean city girls height, sitting height, body weight were greater than Han areas of similar students, while the bust is significantly less than the Han area of Korean students. With the growth of the age, Korean inhabited area of Korean students body shape indicators significantly larger than the differences between the Han nationality area similar students gradually reduced, and form communities was higher than Han 
students development trend of Korean nationality area students.

Han students height was significantly higher than that of two kinds of settlements of Korean students, with lower limb growth as the main features. Korean students trunk length was longer than that of the Han students. The overall level of Han students weight development better than Korean students. Korean city girls thoracic development trend from narrow to wide in chest, narrow chest type characteristic with Han students. Korean students physical development that is better than Han students. body shape is affected by genetic factors and multiple environmental factors. Area of Korean city girls body shape development level and speed of different nationality restriction factor of social and economic factors, cultural factors, educational factors, development, national sports life style etc.

\section{References}

[1] Li Gang. The development level of 1985-2005 height of Jilin Korean and Han students. Chinese Journal of school health, 2008,29 (7): 615-618

[2] Chinese students in physical and health research group. 2010 report on Chinese students' physical fitness and health. Beijing: Higher Education Press, 2012 